\title{
Poder popular e expansão da república romana, 200-150 a.C.
}

Rafael Scopacasa*

\section{RESUMO}

Foi durante a república (509-27 a.C.) que Roma transformou-se de cidade em império. Ao longo desse mesmo período, movimentos sociais em Roma levaram a um crescente envolvimento popular na política. Em que medida a hegemonia romana foi o resultado da agência política das massas? Este artigo discute o poder popular na República Média (c. 250-150 a.C.) e em que medida ele teria modelado a nascente hegemonia romana. Iniciaremos com uma apreciação do debate historiográfico sobre a participação popular na república, ressaltando duas vertentes principais, uma “oligárquica” e outra “democrática”. Em seguida enfocaremos algumas narrativas de Políbio e Tito Lívio, que nos oferecem pontos de partida para refletir sobre a existência de uma cultura política popular e seu papel na hegemonia romana nascente.

Palavras-chave: Roma; república; poder popular; política; historiografia.

\section{ABSTRACT}

It was during the Republican period (509-27 BCE) that Rome's transformation from city to empire took place. This process coincided with growing popular involvement in Roman politics. To what extent was early Roman hegemony an outcome of the political will of the people? In this article I discuss the issue of popular power in the mid-Republic (250-150 $\mathrm{BCE}$ ), and the degree to which popular decision making may have played a role in the rise of early Roman hegemony. I begin by surveying the historiographical debate on popular power in the republic, highlighting two major views, one "oligarchic" and the other "democratic". I then focus on historiographical accounts (Polybius and Livy) which offer an interesting (if complex) vantage point for reflecting on the existence of a popular political culture and its role in the context of early Roman expansionism.

Keywords: Rome; Republic; popular power; politics; historiography.

*Professor da Universidade Federal de Minas Gerais. E-mail: rafaelsco@hotmail.com. 


\section{RESUMEN}

Fue durante la República (509-27 a.C.) que Roma se transformó de ciudad en imperio. A lo largo de ese mismo periodo, movimientos sociales en Roma condujeron a un creciente envolvimiento popular en la política. ¿En qué medida la hegemonía romana fue el resultado de la actuación política de las masas? Este artículo discute el poder popular en la República Media (c. 250-150 a.C.), y en qué grado tendría este poder modelado la naciente hegemonía romana. Iniciaremos con una apreciación del debate historiográfico sobre la participación popular en la República, resaltando dos vertientes principales, una "oligárquica" y otra "democrática". En seguida, enfocaremos algunas narrativas de Polibio y Tito Livio, que nos ofrecen puntos de partida para reflexionar sobre la existencia de una cultura política popular y su papel en la hegemonía romana naciente.

Palabras clave: Roma; República; poder popular; política; historiografía.

Foi durante o período republicano (509-27 a.C.) que Roma transformou-se em um dos impérios mais duradouros da História. ${ }^{1}$ Isso aconteceu ao mesmo tempo que movimentos sociais dentro de Roma levaram a um crescente envolvimento popular na política. Esse processo é conhecido como o "movimento plebeu", que culminou em 287 a.C. quando as decisôes do conselho da plebe ganharam força de lei, graças à aprovação da Lex Hortensia. ${ }^{2}$ Passados apenas vinte anos, Roma iria se envolver em uma série de guerras com rivais mediterrâneos do mais alto escaláo, todos os quais ela viria a derrotar em menos de cinquenta anos, começando por Cartago (202 a.C.), em seguida o reino selêucida (188 a.C.) e finalmente a Macedônia (167 a.C.). Pouco mais de um século após a aprovação da Lex Hortensia, Roma já era a potência hegemônica do Mediterrâneo.

Há controvérsias a respeito da natureza dessa expansão, e se ela pode ser caracterizada como "imperialista": estariam os romanos deliberadamente adotando uma política intervencionista, com a intenção de conquistar povos e territórios — ou, ao contrário, teria sido a expansão uma consequência não pretendida da vitória de Roma em guerras nas quais ela se

\footnotetext{
${ }^{1}$ Trata-se da periodizaçáo tradicional da história romana, cuja utilidade pode muito bem ser questionada: por exemplo, ao pensarmos em um único "período republicano" de 500 anos, corremos o risco de mascarar a existência de diferentes momentos, fases e mudanças compreendidos nesse longuíssimo intervalo de tempo. Para uma recente crítica da periodização tradicional do "período republicano" e propostas alternativas, cf. FLOWER, Harriet. Roman Republics. Princeton: Princeton University Press, 2009. Entretanto, não se pretende contribuir aqui para o debate sobre periodização e cronologia, de modo que adotamos a periodização tradicional, conscientes de suas imperfeiçóes.

${ }^{2}$ Fontes a respeito da Lex Hortensia: Gai Institutiones, I, 3; Iustiniani Institutiones, I, 2; Digesta, I, 2. Sobre o movimento plebeu cf. RAAFLAUB, Kurt (Org.). Social Struggles in Archaic Rome: New Perspectives on the Struggle of the Orders. Oxford: Oxford University Press, 2005.
} 
envolveu por necessidade, e não por escolha? ${ }^{3}$ Dadas as incertezas, o termo "imperialismo" pode não ser o mais adequado para descrever os primeiros séculos de expansão romana. Por outro lado, é relativamente claro que Roma já desempenhava um papel hegemônico no Mediterrâneo no início do século II a.C.: as vitórias sobre Cartago em 202 a.C., e sobre a Macedônia em 167 a.C., deram à cidade uma ascendência relativamente incontestada sobre os outros Estados mediterrânicos.

Coloca-se, assim, um duplo questionamento: primeiro, em que medida essa hegemonia romana teria nascido da agência política das massas? Sabemos que as camadas populares formavam o grosso do exército romano - depois das tropas que os Estados italianos aliados eram obrigados a fornecer. ${ }^{4}$ Mas é bem menos claro se o povo, entendido aqui como a maioria dos cidadãos, foi responsável pelas decisóes políticas que impulsionaram a expansão romana, como as declaraçóes de guerra, os tratados de paz, as respostas às embaixadas estrangeiras, a fundação de colônias e as concessões de cidadania romana a comunidades derrotadas. ${ }^{5}$ Essa questão levanta outra: até que ponto os cidadãos das camadas sociais populares exerciam poder político efetivo, e em que sentido poderíamos dizer que a república romana tinha um caráter democrático? ${ }^{6}$

Já em meados do século II a.C., o historiador Políbio fazia perguntas semelhantes. Políbio acreditava que o grande sucesso de Roma se devia à sua constituição "mista", que teria garantido um equilíbrio delicado, mas tremendamente eficaz, entre massas e elites. ${ }^{8}$

\footnotetext{
3 Para uma apreciação do longo debate sobre a natureza da expansão romana no Mediterrâneo, cf. ECKSTEIN, Arthur. Mediterranean Anarchy, Interstate War, and the Rise of Rome. Berkeley: University of California Press, 2006; ECKSTEIN, Arthur. Rome Enters the Greek East: from Anarchy to Hierarchy in the Hellenistic Mediterranean, 230-170 BC. Oxford: Blackwell, 2012.
}

${ }^{4}$ CORNELL, Timothy. The Beginnings of Rome. Londres: Routledge, 1995. Entende-se aqui que a "plebe" teria incluído, principalmente, os pequenos agricultores que formaram o grosso da população cidadã romana. Entretanto, é importante lembrar que havia alguns plebeus enriquecidos e "elitizados", que desde cedo se uniram aos patrícios por meio do casamento, dando origem à "nobreza" ou nobilitas republicana: cf. BRUNT, Peter. Social Conflicts in the Roman Republic. Londres: Chatto and Windus, 1971. A ambiguidade do termo "plebe" nas fontes é discutida à frente.

${ }^{5}$ Essas questôes não são de todo inéditas: cf. MILLAR, Fergus. The Political Character of the Classical Roman Republic, 200-150 BC. Journal of Roman Studies. Londres: Society for the Promotion of Roman Studies, v. 74, p. 1-19, 1984.

${ }^{6}$ Ibidem, p. 1-3.

${ }^{7}$ POLÍBIO 6.1: "o aspecto do meu trabalho que é o melhor em si mesmo, e o mais instrutivo para os estudantes, é aquele que lhes permite compreender de que maneira, e com que tipo de constituição, ocorreu que quase o mundo inteiro caiu sob o poder de Roma, em pouco menos de 53 anos, um evento certamente sem precedentes." (the feature of my work which was at once the best in itself, and the most instructive to the students of it, was that it would enable them to know and fully realise in what manner, and under what kind of constitution, it came about that nearly the whole world fell under the power of Rome in somewhat less than fifty-three years, - an event

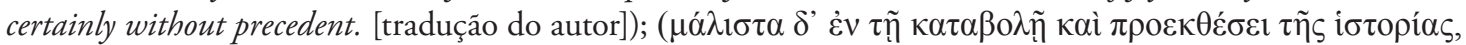

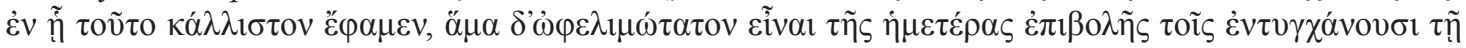

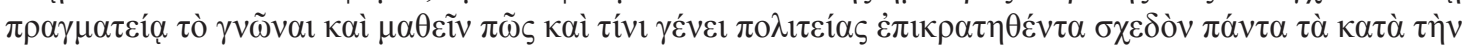

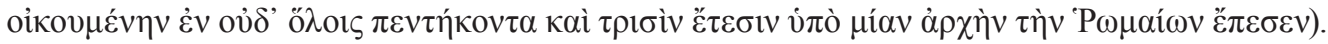

${ }^{8}$ POLÍBIO 6.11: "se olharmos somente para o poder dos cônsules, estaríamos inclinados a considerar a 
Para Políbio, não havia dúvida de que os cidadãos romanos como um todo (e não somente as elites socioeconômicas) participavam na tomada de decisóes: teria sido por causa dessa participação que a população conseguia frear o poder e os interesses da aristocracia: assim, na lógica de Políbio, mantinha-se a coesão social e evitavam-se radicalismos que ameaçassem a existência da cidade, como também fortalecia-se a cidade, de modo a possibilitar sua expansão. Políbio enfatiza que "a maioria" (hói pollói) tinha direito ao voto nas assembleias, nas quais eram tomadas as principais decisóes, inclusive declaraçóes de guerra e paz. Ele também nota que a maioria dos cidadãos podia eleger magistrados e oficiais públicos nessas mesmas assembleias, inclusive os cônsules; e que integrantes do povo podiam participar como juízes em tribunais populares.

Entretanto, durante boa parte do século XX muitos historiadores viram o relato de Políbio como idealizado e enganoso: embora a população participasse formalmente das assembleias, e embora todos os cidadãos tivessem o direito de voto, na prática, a desigualdade socioeconômica teria concentrado o exercício de poder político nas mãos de uma pequena elite dirigente, cujo principal instrumento era o senado. Essa elite era formada por grandes proprietários de terras e ricos comerciantes - não somente as famílias patrícias como também aquelas famílias plebeias que haviam enriquecido, que juntas formavam os ditos "nobres" ou nobiles. Teria sido essa elite a principal interessada em promover a expansão romana: as enormes riquezas advindas da exploração dos territórios anexados teriam, supostamente, se concentrado nas mãos dessa casta seleta, cujos membros teriam monopolizado o acesso a cargos administrativos lucrativos como os governos das províncias. ${ }^{10}$ Por meio do clientelismo, as elites teriam garantido a lealdade e o consentimento dos cidadãos pobres. Consequentemente, as decisóes tomadas pelo povo nas assembleias nem sempre (ou, segundo alguns estudiosos, quase nunca) representavam os "reais" interesses da maioria. Mesmo porque as leis votadas nas assembleias não eram elaboradas pela maioria, mas vinham "de cima”, do senado. Em outras palavras, a própria gama de escolhas oferecidas à população teria sido delimitada pela aristocracia. Participação popular, talvez, mas passiva e só aparente?

Este artigo discute a questão do poder popular durante o período republicano médio (c. 250-150 a.C.), e em que medida esse poder popular teria influenciado a expansão romana

constituição romana como despótica; se olharmos só para o Senado, como aristocrática; e se, finalmente, considerarmos o poder dos muitos/da maioria (tôn pollôn), pareceria um caso claro de democracia." (if we confine our observation to the power of the Consuls we should be inclined to regard it as despotic; if on that of the Senate, as aristocratic; and if finally one looks at the power possessed by the people it would seem a clear

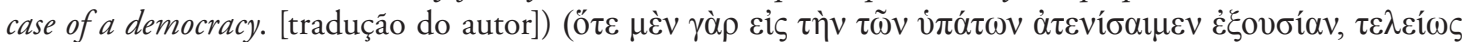

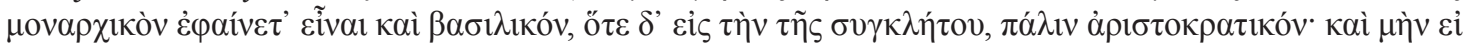

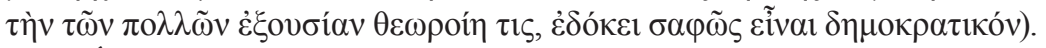

${ }^{9}$ POLÍBIO, 6.1-11.

${ }^{10}$ Cf., por exemplo, HOPKINS, Keith. Conquerors and Slaves. Cambridge: Cambridge University Press, 1978. p. 1-6. 
inicial. Começaremos com uma apreciação do debate historiográfico sobre a participação popular na república, que vem se desenvolvendo desde o início do século XX, ressaltando duas vertentes principais: a primeira, que defende uma visão "oligárquica" da república, e a segunda, que enfatiza o caráter "democrático" do sistema. Considerando a vastidão da historiografia sobre o tema, e os limites do presente artigo, optamos por centrar a discussão em alguns autores que tiveram um papel particularmente importante no desenvolvimento do debate historiográfico: Matthias Gelzer, Ronald Syme, Lily Ross-Taylor, Fergus Millar, Peter Brunt, Robert Morstein-Marx e Henrik Mouritsen. Embora essa amostragem não seja exaustiva, todos os autores selecionados contribuíram de modo fundamental para o debate historiográfico, conforme explicado à frente.$^{11}$ Em seguida, o foco será colocado em uma seleçâo das fontes historiográficas antigas, a saber, Políbio e Tito Lívio, que nos oferecem pontos de partida privilegiados para refletirmos sobre o papel do povo romano na hegemonia romana nascente. Isso envolverá discutir até que ponto a população participava da política de maneira deliberada e autônoma.

\section{O debate historiográfico: um panorama}

Todos sabemos que a palavra "república" origina-se da expressão latina res publica, frequentemente encontrada em textos clássicos do século I a.C. como o de Re Publica de Cícero. Mas cem anos antes, no século II a.C., a expressão não era res publica e sim res poplica. A grafia diferente é atestada em uma inscrição de 160 a.C., que registra a resposta "do senado e do povo romano" a uma embaixada da cidade latina de Tibur, uma das várias cidades-Estados aliadas a Roma na época. É até possível que antes, no século III a.C., a grafia fosse res populica, ainda mais próxima da palavra populus. ${ }^{12}$

No contexto dos séculos III e II a.C., portanto, o caráter popular da república romana estava evidente inclusive no seu nome. Contudo, desde o início do século XX, consolidou-se na historiografia europeia a dita tese "oligárquica" sobre a república romana: em síntese, essa tese rejeitava o relato polibiano de que o povo, no sentido da maioria do corpo de cidadáos, exercera poder político efetivo. Ao contrário, o poder popular de que fala Políbio teria sido uma espécie de fachada, cujo propósito era encobrir a oligarquia que realmente controlava Roma e o seu império nascente.

Em 1912, Matthias Gelzer, à época professor da Universidade de Greifswald, na Suíça, publicou $A$ nobreza da república romana..$^{13}$ Essa foi a primeira obra que siste-

\footnotetext{
${ }^{11}$ Outros autores além dos supracitados, também importantes para a compreensão do debate historiográfico (como Karl Holkeskamp, Egon Flaig e Alexander Yakobson), são discutidos na segunda parte deste artigo. ${ }^{12}$ Poplica: CIL I $\mathrm{I}^{2}$ 586; populica: cf. CIL I 28 (Populicus). Cf. WISEMAN, Timothy. Remembering the Roman People. Oxford: Oxford University Press, 2009, p. 1.

${ }^{13}$ GELZER, Matthias. The Roman Nobility. Oxford: Blackwell, 1969.
} 
maticamente defendeu a tese de que a república romana havia sido uma oligarquia e, consequentemente, que a transição da república para o principado no final do século I a.C. fora marcada mais por continuidades do que por rupturas. Segundo Gelzer, muito antes da ascensão do primeiro imperador o povo romano já deixara de exercer participação política real. Falar em democracia durante a república seria, portanto, um absurdo. Como argumento basilar, Gelzer propôs que o comportamento dos eleitores romanos na república era determinado pelos vínculos de clientelismo que, ao seu ver, haviam caracterizado a sociedade romana desde tempos imemoriais. Esse sistema de trocas de favores pessoais (geralmente entre uma família rica, cujos membros prestavam auxílio jurídico ou material a famílias mais humildes, em troca da lealdade e do apoio desses últimos, por várias geraçóes) teria cancelado quaisquer "interesses de classe” que poderiam existir entre os eleitores mais pobres e socialmente marginalizados. Nas palavras do próprio Gelzer, a sociedade romana era:

permeada por diversas relaçóes fundamentadas no conceito de fides e em vínculos pessoais, e os mais fortes desses vínculos eram o clientelismo sobre os tribunais e comunidades, junto com amizade política e obrigação financeira (...) O homem mais poderoso era aquele que, em virtude dos seus clientes, era capaz de mobilizar o maior número de eleitores. ${ }^{14}$

Em outras palavras, aproveitando-se da desigualdade socioeconômica entre os cidadãos, os mais ricos teriam criado laços de dependência com os mais pobres, colocando-os sob a obrigação moral de apoiar decisôes políticas que protegiam os interesses e os privilégios da elite. Vale ressaltar que a importância do clientelismo na república já havia sido defendida algumas décadas antes de Gelzer por Fustel de Coulanges, em um estudo de 1877 sobre a história das instituições políticas na França antiga. O objetivo de Coulanges era demonstrar que o sistema feudal da França medieval tinha suas raízes no clientelismo romano. ${ }^{15}$ Contudo, Gelzer foi o primeiro historiador a defender, de maneira sistemática, que o clientelismo permeava todas as relaçóes sociais em Roma, impossibilitando assim o desenvolvimento de qualquer tipo de organização remotamente democrática, que dirá de uma democracia nos moldes atenienses.

Para sustentar sua tese oligárquica, Gelzer utilizou fontes textuais da república tardia (133-27 a.C.), as quais enfatizam a importância dos clientes para o poder da aristocracia. Um bom exemplo, do qual Gelzer faz uso, é o trecho de Salústio tirado da sua "Guerra de Jugurta", em que o autor romano observa que "nobreza antiga, as façanhas de seus antepas-

\footnotetext{
${ }^{14}$ Ibidem, p. 269: (permeated by multifarious relationships based on fides and personal connections, the principal forms of which were patrocinium in the courts and over communities, together with political friendship and financial obligation (...) Thus the most powerful man was he who by virtue of his clients and friends could mobilise the greatest number of voters. [tradução do autor])

${ }^{15}$ Ibidem, p. 62.
} 
sados, o poder de seus parentes, e a multidáo de clientes" garantiam o poder do grupo que ele denomina "nobres" ${ }^{16}$ Convencido da veracidade de tais relatos, para Gelzer a única conclusão lógica era que Políbio simplesmente não entendera como a política romana realmente funcionava, devido à sua incapacidade (ou indisposição) de enxergar as "forças ocultas" que efetivamente regiam a república.

Não demorou para que as ideias de Gelzer atravessassem o canal da Mancha e chegassem à Inglaterra. Em 1939, o eminente romanista Ronald Syme, de Oxford, publicou The Roman Revolution, uma análise sagaz da transição da república para o governo monárquico de Augusto, que modificou profundamente a maneira como esse período era pensado na historiografia. ${ }^{17}$ A tese central de Syme (revolucionária para a época) era que a passagem da república para o principado não representara uma ruptura, mas sim uma continuidade. Isso porque já durante a república a vida política romana teria sido monopolizada por um grupo seleto de famílias aristocráticas; tal situação teria se mantido basicamente a mesma após o assassinato de Júlio César, as guerras civis e a ascensão de Otaviano/Augusto.

Apesar de seu caráter inovador, não é difícil ver como o argumento de Syme tem suas raízes na tese oligárquica de Gelzer. Syme chega a afirmar (aparentemente sem receio de exagero) que a constituição da república era uma "farsa":

Em todas as épocas, não importa a forma e o nome do regime - monarquia, república, ou democracia - uma oligarquia esconde-se atrás da fachada; e a história romana, tanto republicana quanto imperial, é a história da classe governante. (...) A constituiçáo romana era uma cobertura e uma farsa. ${ }^{18}$

Ao afirmar que a constituição da república era uma "farsa", Syme parece estar parafraseando Júlio César. Em sua biografia de César, Suetônio comenta que, entre as várias coisas "inadequadas" que o estadista dizia em público, estava a afirmação de que a república não era nada além de um simples nome, sem substância ou realidade. ${ }^{19}$

No pós-guerra, a tese "oligárquica" atravessou o Atlântico e popularizou-se nos Estados Unidos. Um dos primeiros resultados dessa disseminação foi o estudo de Lily Ross Taylor sobre "políticas de partido" na época de Júlio César. ${ }^{20}$ Taylor centrou sua discussão na questão do sistema eleitoral romano, no qual o voto não era individual, mas coletivo, diferentemente

\footnotetext{
${ }^{16}$ SALÚSTIO, Guerra de Jugurta, 85.4 (their ancient rank, the heroic actions of their ancestors, the power of their relatives and connections, their numerous dependents [clientela] [tradução do autor]); (vetus nobilitas, maiorum fortia facta, cognatorum et adfinium opes, multae clientelae). Ver também Cícero, Pro Murena, 70.

${ }^{17}$ SYME, Ronald. The Roman Revolution. Oxford: Clarendon, 1939.

${ }^{18}$ Ibidem, p. 7-15: "In all ages, whatever the form and name of government, be it monarchy, republic, or democracy, an oligarchy lurks behind the façade; and Roman history, Republican or Imperial, is the history of the governing class (...) The Roman constitution was a screen and a sham" (tradução nossa).

${ }^{19}$ SUETÔNIO, Divus Iulius, 77.

${ }^{20}$ TAYLOR, Lily Ross. Party Politics in the Age of Caesar. Berkeley: University of California Press, 1949.
} 
da Atenas democrática. Esse sistema de voto coletivo, no qual os cidadãos eram agrupados em centúrias e tribos, teria (supostamente) garantido que a maior parte do poder político ficasse nas mãos dos fazendeiros, ao passo que a população de artesãos urbanos ficava subordinada a eles. ${ }^{21}$ Isso porque os eleitores romanos, ao que tudo indica, estavam aparentemente distribuídos nas tribos eleitorais de maneira desigual. Segundo os cálculos de Taylor, das 35 tribos, as quatro tribos ditas "urbanas" incluíam praticamente todos os trabalhadores pobres da cidade de Roma, enquanto as 31 tribos remanescentes, ditas "rurais", eram compostas por proprietários de terra. Com base nisso, a autora concluiu que o próprio sistema eleitoral fazia com que o voto dos mais pobres contasse menos do que o voto dos mais ricos - que veio a ser uma das mais arraigadas teses sobre a política na república.

As camadas populares ficaram relegadas a esse papel de "espectadores passivos" da política romana até a década de 1980. Foi então que uma série de questionamentos despontou na historiografia, vindo a formar uma nova vertente sobre a natureza do regime republicano, que recebeu o nome de "vertente democrática". ${ }^{22}$ Seu apelo foi tal que, ao final da década de 1990, ela já podia ser considerada a nova visáo ortodoxa.

Um dos primeiros proponentes da tese democrática foi o britânico Fergus Millar. Em 1977, ele publicou um estudo muito influente sobre o caráter divino do imperiador romano. Em seguida, em uma série de artigos publicados na década de 1980, Millar voltou sua atenção para o período republicano, e questionou sistematicamente a tese "oligárquica" de Gelzer. Millar constatou claramente que sua intenção era demonstrar que Políbio tinha razão, e que seus intérpretes modernos estavam errados em relação à natureza da república romana. ${ }^{23}$ Seu argumento original, em essência, foi que o poder do povo havia sido muito mais direto, consciente e eficaz do que se supusera até então.

Millar propôs que os modernos haviam exagerado a importância do clientelismo na vida política romana. ${ }^{24} \mathrm{~A}$ partir de um reexame das fontes disponíveis, ele buscou demonstrar que, apesar dos inegáveis privilégios dos aristocratas, as massas conseguiram conquistar um grau considerável de poder político através de uma série de lutas e movimentos sociais que geraram re-

\footnotetext{
${ }^{21}$ Ibidem, p. 51.

${ }^{22}$ Cf., por exemplo, NORTH, John. Politics and Aristocracy in the Roman Republic. Classical Philology. Cambridge: Cambridge University Press, v. 85, n. 4, p. 277-287, out. 1990.

${ }^{23}$ MILLAR, Fergus. The political character of the Classical Roman Republic, 200-150 BC, op. cit., p. 3.

${ }^{24}$ Ibidem, p. 2: "Diz-se que Políbio não conseguia ver as estruturas sociais que garantiam a dominação dos nobres; essas devem ser as relaçôes de clientelismo e dependência que, supostamente, determinavam a tomada de decisóes políticas, fazendo da participação popular algo passivo e nominal. Mas a existência dessas estruturas é, ela mesma, uma hipótese moderna, que tem muito pouco apoio nas nossas fontes. Está na hora de considerarmos outra hipótese, a de que Políbio não as viu porque elas não existiam." (Polybius, it is claimed, failed to see the social structures which ensured the domination of the nobiles; that must mean the relationships of patronage and dependence which supposedly dominated Roman political decision-making and rendered popular participation passive and nominal. But the existence of these structures is itself a modern hypothesis, which has very little support in our evidence. It is time to turn to a different hypothesis, that Polybius did not see them because they were not there [tradução do autor]).
} 
sultados concretos. O povo teria exercido esse poder de maneira conscientente e deliberada por intermédio das assembleias, especialmente no período entre 200 e 150 a.C. Em outras palavras, embora Roma não fosse uma democracia radical nos moldes de Atenas, ainda assim havia um elemento democrático no sistema romano, tal como Políbio já assinalara no século II a.C. ${ }^{25}$

Ao discutir o poder do eleitorado em Roma, Millar ressaltou a importância da figura dos oradores, aqueles homens, geralmente de elite, que falavam ao povo nos comícios e na assembleias, na tentativa de convencê-lo a votar de determinada maneira. Essa prática, realizada antes de qualquer votaçáo importante na assembleia, sugere que o apoio popular não era garantido, mas tinha de ser conquistado.

Embora Millar seja o mais ferrenho defensor do caráter democrático da república, outros historiadores já vinham desenvolvendo argumentos parecidos desde os anos 1960. Já em 1965, por exemplo, Peter Brunt criticava a ênfase excessiva dada à importância do clientelismo na sociedade romana, visto que havia muitos outros fatores que teriam influenciado o comportamento dos eleitores. ${ }^{26}$ Brunt atentou ao problema da falta de informação, lembrando que raramente podemos determinar por que os eleitores decidiam apoiar certos candidatos e não outros, sendo que muitas vezes não temos como saber quais candidatos foram rejeitados. ${ }^{27}$ É inegável que nossas fontes, parciais e fragmentárias, dificultam o entendimento do comportamento dos eleitores romanos.

Entretanto, as poucas fontes que temos não parecem revelar um contexto em que famílias aristocráticas estavam tranquilas e seguras na sua manipulação do povo. Muito pelo contrário, documentos como as oraçôes e as cartas de Cícero sugerem uma constante preocupação com a imprevisibilidade das eleiçôes nas assembleias, sugerindo a necessidade de garantir votos favoráveis por meio de uma série de expedientes que não os vínculos de clientelismo:

Pois qual mar, qual Euripus você acha que existe, que seja suscetível a tais comoçôes, a agitaçóes táo grandes e numerosas, como as tempestades e marés que influenciam as assembleias? O intervalo de um dia — de uma só noite — frequentemente lança tudo em confusão. $\mathrm{O}$ boato mais ligeiro às vezes muda toda a opinião das pessoas. Frequentemente, até mesmo tudo é feito sem qualquer causa aparente, de uma maneira totalmente em desacordo com as opiniốes expressas, ou que são realmente entretidas. De modo que, às vezes, o povo se espanta que o que foi feito, como se não tivesse sido ele próprio que o fizera. ${ }^{28}$

\footnotetext{
${ }^{25}$ MILLAR, Fergus. The political character of the Classical Roman Republic, 200-150 BC, op. cit., p. 2: "nós não podemos entender a política romana se nossa visão não abarcar, além do poder dos indivíduos que ocupavam magistraturas e o poder coletivo do Senado como um todo, o poder do povo tal como era representado, ainda que imperfeitamente, nas suas assembleias." (we cannot understand Roman politics if our view does not encompass, along with the power of individuals holding office and the collective power of the Senate as a body, the power of the people as represented, however imperfectly, in their assemblies [tradução do autor]).

${ }^{26}$ BRUNT, Peter. The Fall of the Roman Republic and Related Essays. Oxford: Clarendon, 1988, p. 431.

${ }^{27}$ Ibidem, p. 426.

${ }^{28}$ CÍCERO, Pro Murena, 35: "For what sea, what Euripus do you think exists, which is liable to such commotions,
} 
Em um mundo assim inconstante e inseguro, um aristocrata que quisesse fazer carreira política provavelmente não poderia contar somente com a lealdade dos seus clientes: primeiro porque, como podemos inferir a partir do testemunho de Cícero, essa lealdade não estava garantida na prática, até possivelmente nos casos em que o cliente teria recebido constante apoio do seu benfeitor; segundo, porque havia, ao que tudo indica, muitas outras variáveis que interferiam no processo. Com base no testemunho de Cícero, Millar atentou ao fato de que os aristocratas romanos estavam constantemente preocupados com a opinião pública. Essa preocupação simplesmente não faria sentido se não houvesse a possibilidade real de que a vontade do povo influenciasse o rumo da política.

Apesar das críticas e respostas negativas, as ideias originais de Millar causaram euforia, especialmente entre jovens estudiosos na Inglaterra e nos Estados Unidos. O próprio Millar continuou desenvolvendo sua tese, dando-lhe um caráter cada vez mais radical. Tudo isso contribuiu para que, ao final dos anos 1990, a tese democrática viesse a ser a nova ortodoxia e abrisse novas linhas de investigação sobre os processos "democráticos" que teriam vigorado na república.

Uma contribuição fundamental nesse sentido é o estudo de Robert Morstein-Marx sobre a oratória na república tardia. ${ }^{29}$ Logo nas primeiras páginas, o autor constata sua convicção de que a república romana pode, e deve, ser vista como uma democracia, já que toda e qualquer legislação tinha que ser aprovada por voto popular. ${ }^{30}$ Partindo dessa premissa, Morstein-Marx analisa as estratégias discursivas que os oradores empregavam para ganhar o apoio do povo às leis e medidas que eles propunham em assembleia. $\mathrm{O}$ próprio fato de que era necessário elaborar tais estratégias persuasivas sugere certo grau de soberania da vontade popular: para conseguir o apoio popular a determinada causa, os magistrados tinham que ser convincentes; caso contrário, o povo parece ter estado livre para seguir outros cursos de ação. Por outro lado, Morstein-Marx demonstra como as camadas populares eram suscetíveis às manipulaçóes dos oradores mais exímios, em sua maioria homens de elite, que dispunham de tempo e recursos para receber uma educação em retórica. Em outras palavras, apesar da vontade soberana do povo ser uma realidade,

- to such great and various agitations of waves, as the storms and tides by which the comitia are influenced? The interval of one day, - the lapse of one night - often throws everything into confusion. The slightest breeze of rumour sometimes changes the entire opinions of people. Often, even, everything is done without any apparent cause, in a manner entirely at variance with the opinions that have been expressed, or that indeed, are really entertained; so that sometimes the people marvels that that has been done which has been done, as if it were not itself that has done it" (tradução do autor); (Quod enim fretum, quem Euripum tot motus, tantas, tam varias habere putatis agitationes commutationesque fluctuum, quantas perturbationes et quantos aestus habet ratio comitiorum? Dies intermissus aut nox interposita saepe perturbat omnia, et totam opinionem parva non numquam commutat aura rumoris. Saepe etiam sine ulla aperta causa fit aliud atque existimaris, ut non numquam ita factum esse etiam populus admiretur, quasi vero non ipse fecerit).

${ }^{29}$ MORSTEIN-MARX, Robert. Mass Oratory and Political Power in the Late Roman Republic. Cambridge: Cambridge University Press, 2004.

${ }^{30}$ Ibidem, p. 8. 
essa vontade estaria sujeita a manipulaçóes por parte da elite — a qual, aparentemente, soube movimentar as massas de maneira eficaz em várias ocasióes. Podemos notar aqui certo distanciamento das teorias mais radicais de Millar, e uma leitura mais equilibrada da tese oligárquica. Talvez por esse motivo Morstein-Marx tenha mais sucesso do que Millar em explicar como, apesar da soberania popular, a aristocracia romana conseguiu legitimar a sua autoridade perante o povo com certo sucesso.

Em contrapartida, dentre os historiadores mais críticos de Millar, alguns reafirmaram a tese oligárquica com argumentos novos. Talvez o mais eloquente seja Henrik Mouritsen, que demonstrou que havia fatores que dificultavam seriamente a participação popular na política, além do clientelismo. Por causa da desigualdade socioeconômica que caracterizava a sociedade romana, e que parece ter ficado maior conforme a cidade se expandia, e de uma pequena elite de governadores de províncias que enriquecia em uma escala jamais vista, apenas uma parcela pequena do corpo de cidadáos teria tido o tempo e os recursos necessários para dedicar-se à política. A conquista de novos territórios, e o envio de plebeus a colônias distantes (primeiro na Itália e depois na África, Grécia e península ibérica), teriam feito com que boa parte dos cidadãos de baixa e média renda vivesse muito longe de Roma, tornando difícil — ou até mesmo impraticável — que esses cidadãos comparecessem às várias eleiçôes que aconteciam na cidade ao longo do ano. $\mathrm{O}$ simples fato de que pequenos camponeses, que formavam o grosso da plebe, precisavam trabalhar para ganhar seu sustento, tornaria o comparecimento a assembleias algo custoso e oneroso, e eliminaria — ou dificultaria ao extremo - quaisquer ambiçóes de carreira política entre pessoas dessa condição social.

Por outro lado, é também verdade que as elites dependiam das massas para ter acesso aos tão cobiçados cargos políticos — sendo esse um dos principais argumentos dos defensores da visão "democrática” da república. Cícero, por exemplo, reconhece abertamente que, mesmo na sua república ideal, seria necessário que a elite concedesse certa dose de liberdade ao povo para que houvesse equilíbrio no sistema. ${ }^{31} \mathrm{Ou}$ seja, na prática, Cícero sabia que o poder político do povo era algo impossível de negar ou anular. Como afirma Alexander Yakobson, "o apoio e a aquiescência do povo não podiam ser exigidos: eles tinham que ser merecidos". ${ }^{2}$

\section{Voltando às fontes: o povo e a hegemonia romana nascente}

Conforme podemos deduzir do panorama apresentado, até agora o debate acerca do poder popular na república tem se limitado ao período da república tardia. Esse período compreende, grosso modo, os cem anos entre as reformas agrárias propostas por Tibério

\footnotetext{
${ }^{31}$ CÍCERO, República, 1.43 .

32 YAKOBSON, Alexander. Popular power in the Roman Republic. In: ROSENSTEIN, Nathan; MORSTEIN-MARX, Robert (Orgs.) A Companion to the Roman Republic. Oxford: Blackwell, 2006, p. 398 (The People's acquiescence and support could not be commanded — it had to be earned [tradução nossa]).
} 
Graco em 133 a.C., e a ascensão de Otaviano-Augusto por volta de 31-27 a.C. O enfoque específico nessa última fase da república é compreensível, já que a grande maioria das nossas fontes datam justamente desse período. Em contrapartida, sabe-se ainda muito pouco sobre os séculos anteriores, quando a nascente hegemonia romana tomou forma.

Para essa época remota e obscura, temos dois principais guias: Políbio e Tito Lívio. Ambos os autores narram episódios importantes que marcaram a consolidação da hegemonia romana no Mediterrâneo, sobretudo entre 202 a.C., quando Cartago foi derrotada pela segunda vez, e 146 a.C., quando os romanos saquearam Corinto. Esse é o período conhecido como a "república média" (250-150 a.C.).

É importante reconhecer que nem Políbio nem Tito Lívio nos dáo acesso direto à vida política de Roma republicana. O primeiro obstáculo nesse sentido é o caráter tardio das suas narrativas. Dos dois historiadores, o único que poderia ser considerado um testemunho contemporâneo aos eventos narrados é Políbio, embora ele próprio tenha escrito a sua "História" no "início do fim" da república (150-120 a.C.). O problema é particularmente acentuado no caso de Lívio, que escreveu no final do século I a.C., cerca de 200 anos após os eventos narrados. Náo se sabe ao certo como ambos os autores obtiveram a informaçáo sobre a história de Roma dos séculos III e II a.C., quando muitos dos episódios que nos interessam teriam ocorrido. Evidentemente, as narrativas de Políbio e Tito Lívio são informadas pelos contextos históricos em que foram escritas, pelos pontos de vista e objetivos de cada autor, e pelas expectativas de seus respectivos públicos. ${ }^{33}$ Tais variáveis informam a maneira como o passado republicano é representado nesses textos. Por outro lado, o fato de esses textos serem (relativamente) tardios não impede que nós os abordemos como fontes históricas sobre a República média. Ocasionalmente, tanto Políbio como Tito Lívio mencionam historiadores romanos anteriores, cujas obras eles consultaram, dos quais o mais antigo - Fabius Pictor, autor da primeira história de Roma de que se tem conhecimento - viveu na segunda metade do século III a.C. Portanto, é razoável supor que as narrativas de que dispomos estão, ao menos em parte, fundamentadas em relatos e documentos anteriores, mais próximos ao período que nos interessa (c. 200-150 a.C.).

Em todos os episódios considerados a seguir, o povo (populus em Lívio; demos, óchlos ou hói pollói em Políbio), e às vezes a plebe, especificamente, figuram como protagonistas em tomadas de decisões que marcaram a trajetória inicial da expansão hegemônica romana. Há, por exemplo, uma série de trechos que colocam o "povo romano" como responsável por declaraçóes de guerra e pela conclusão de tratados de paz, os quais são feitos somente após consulta e aprovação popular. Esse é o caso do trecho em que Lívio relata como o populus decidiu terminar a segunda Guerra Púnica em 202 a.C.:

\footnotetext{
33 Para uma abordagem diferente, que discute a obra de Tito Lívio como documento histórico acerca do contexto em que foi produzida (e não do período narrado na obra), cf. SCOPACASA, Rafael. Essere sannita: rappresentazioni d'un popolo italico nelle fonti letterarie e storiografiche antiche. Campobasso: Istituto Regionale per gli Studi Storici del Molise, 2007.
} 
Então Manius Acilius e Quintus Minucius, tribunos da plebe, trouxeram para o povo (populus) a questão de saber se era a vontade e ordem do povo que o senado decretasse a paz com os cartagineses, quem deveria conceder a paz, e quem deveria trazer o exército da África. Quanto à paz, todas as tribos votaram que sim: que Publius Scipio concedesse a paz, que ele também trouxesse de volta o exército. Assim sendo, o senado decretou que Publius Scipio, a conselho dos dez emissários, fizesse as pazes com o povo cartaginês, nas condiçóes que ele julgasse adequadas. $^{34}$

De acordo com Lívio, antes que o senado pudesse tomar qualquer providência o povo deveria ser consultado, inclusive sobre quem deveria conceder a paz aos cartagineses e quem deveria trazer o exército de volta da África. Mas permanece a difícil questão de quem seria esse "povo", exatamente. Seria esse um termo "fachada" que encobriria a dominação silenciosa da elite?

O vocabulário empregado por Políbio é ligeiramente diferente. Por exemplo, ele afirma que em 167 a.C. a "multidão" (ochlos) rejeitou a proposta de declarar guerra contra o Estado grego de Rodes: "Mas quando um dos pretores subiu ao palanque e exortou a multidão (ochlos) a declarar guerra contra Rodes, então em verdade os embaixadores de Rodes ficaram fora de si de medo, por causa do perigo que ameaçava a sua pátria (patrís)." ${ }^{5} \mathrm{O}$ fato de Políbio escrever que os embaixadores ródios estavam temendo seriamente pela sua "pátria”, por causa da possibilidade que a guerra fosse declarada, sugere que a "multidão" tinha, de fato, o poder de iniciar hostilidades naquela ocasião; isso significaria, mais uma vez, uma participação popular direta em decisóes cruciais de política externa. Porém, a mesma ambiguidade interpretativa que encontramos em Lívio reaparece aqui: Políbio nos infoma que o senado já havia rejeitado a proposta de guerra contra Rodes. Isso nos leva a indagar até que ponto a "multidáo" poderia ter efetivamente contrariado a vontade dos senadores, caso o senado tivesse sido favorável à guerra.

De modo geral, tanto Políbio quanto Lívio parecem sugerir que o senado não tomava nenhuma providência em assuntos de política externa sem que o povo antes expressasse sua

\footnotetext{
${ }^{34}$ LIVIO 30.43: (Thereupon Manius Acilius and Quintus Minucius, tribunes of the plebs, brought before the people the question whether it was their will and command that the senate should decree that peace be made with the Carthaginians; and whom they should command to grant that peace, and whom to bring the army back from Africa. In regard to the peace all the tribes voted affirmatively: that Publius Scipio should grant the peace, that he also should bring back the army. In accordance with this enactment the senate decreed that Publius Scipio on the advice of ten envoys should make peace with the Carthaginian people upon such terms as he saw fit [tradução do autor]). (Tum M'. Acilius et Q. Minucius tribuni plebis ad populum tulerunt vellent iuberentne senatum decernere ut cum Carthaginiensibus pax fieret; et quem eam pacem dare, quemque ex Africa exercitum deportare iuberent. De pace 'Uti rogas'omnes tribus iusserunt; pacem dare P. Scipionem, eundem exercitum deportare. Ex hac rogatione senatus decrevit ut P. Scipio ex decem legatorum sententia pacem cum populo Carthaginiensi quibus legibus videretur facere). ${ }^{35}$ POLÍBIO 30.4.4-6: (But when one of the praetors mounted the Rostra and urged the people to declare war against Rhodes, then indeed they were beside themselves with terror at the danger that threatened their country [traduçâo

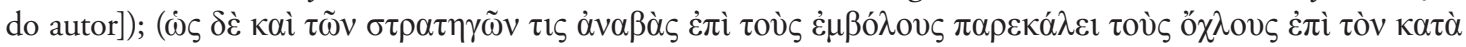

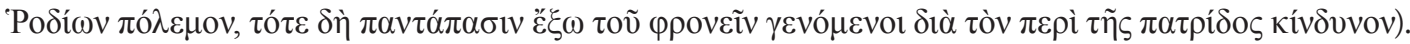


vontade. Tomemos, por exemplo, o ocorrido em 191 a.C., quando considerava-se a possibilidade de declarar guerra contra Antíoco III, o rei selêucida:

Os senadores ordenaram que a questão fosse colocada ao povo (populus), para determinar se era a vontade e intençấo do povo que a guerra fosse feita contra Antíoco e seus aliados. Se a proposta fosse aceita, os cônsules deveriam levar a questấo novamente até o senado. P. Cornelius colocou a questáo para o povo, e foi aceita; o senado entáo decretou que os cônsules deveriam sortear o comando das províncias da Grécia e da Itália. ${ }^{36}$

De acordo com Lívio, a decisáo do povo guiou a conduta do senado. Entretanto, permanece a pergunta: o senado poderia ter agido de forma diferente nessa ocasiáo se o povo tivesse tomado outra decisão? A frase de Lívio "que a questão fosse colocada ao povo, para determinar se era a vontade e intenção do povo", é na verdade uma fórmula recorrente em sua obra. Algo muito semelhante parece ter ocorrido no terceiro ano da guerra entre Roma e o reino selêucida, em 188 a.C., quando Antíoco III decidiu enviar dois embaixadores (Antípater e Zêuxis) até o senado, com uma proposta de paz. O senado aceitou a proposta, mas os juramentos só foram trocados uma vez que o povo (demos) ratificou a decisão:

O Senado então pediu que entrassem Antípater e Zêuxis, os embaixadores de Antíoco, e tendo eles feito seu discurso em um tom de súplica e humildade, votou-se pela aprovação do acordo entre Antíoco e Scipião que havia sido feito na Ásia. Poucos dias depois, o povo (demos) ratificou a decisão e juramentos foram devidamente trocados com Antípater e seu colega. ${ }^{37}$

Seria o papel do povo em tais instâncias uma simples formalidade, sem possibilidade real de intervenção ou transformação política? Vale lembrar, aqui, que uma das críticas mais contundentes à tese "democrática" de Millar é a de que não se pode confundir os direitos formais dos cidadãos, com o que de fato esses cidadãos podem fazer na prática do dia a dia.

\footnotetext{
${ }^{36}$ LIVIO 36.1.4-6: (When this report was laid before the senate their minds were at rest so far as the sanctions of religion were concerned and they ordered the question to be submitted to the people. "Whether it was their will and intention that war should be undertaken against Antiochus and those who were of his party?" [tradução do autor]); (Haec cum renuntiata essent, solutis religione animis patres rogationem ad populum ferri iusserunt, vellent iuberentne cum Antiocho rege, quique eius sectam secuti essent, bellum iniri).

${ }^{37}$ POLÍBIO 21.24.2-3: (The Senate next caused Antipater and Zeuxis, the ambassadors of Antiochus, to be introduced: and on their speaking in a tone of entreaty and supplication, an approval of the agreement made by him with Scipio in Asia was voted. A few days later the people also ratified it, and oaths were accordingly



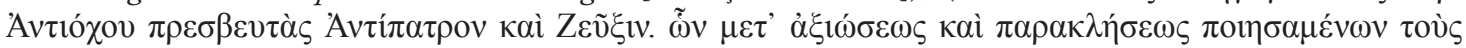
$\lambda$ ó

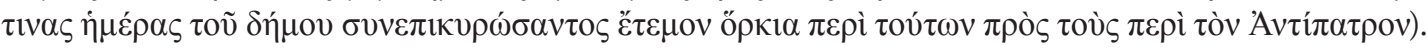


Em outras palavras, pode-se dizer que Millar é excessivamente "formalista" ou "legalista" na sua visão da vida política sob a república. ${ }^{38}$

Por outro lado, não precisamos ir ao extremo de Egon Flaig, segundo o qual as assembleias republicanas não passavam de "instituiçôes formadoras de consenso" já que muitas vezes o povo parece simplesmente concordar com a decisão do senado. ${ }^{39} \mathrm{Na}$ verdade, há casos em que Lívio parece sugerir que o povo podia ir contra os interesses de figuras dirigentes: por exemplo, o trecho em que ele afirma que a plebe, especificamente, foi responsável pela paz concluída com o rei Filipe V da Macedônia, em 196 a.C.:

E o cônsul poderia ter vencido, não tivessem Quintus Marcius Ralla e Caius Atinius Labeo, tribunos do povo (populus), anunciado que iriam vetar qualquer ação, se a questão não fosse submetida antes à plebe, para determinar se ela desejava e ordenava que a paz fosse feita com o rei Filipe. Essa moção foi, então, colocada diante da plebe reunida no Capitólio; todas as 35 tribos votaram "sim". ${ }^{40}$

As velhas dúvidas sobre até que ponto podemos confiar em Lívio imediatamente vêm à tona, considerando que ele escreveu seu texto centenas de anos após os eventos narrados, e a partir de fontes que eram, elas próprias, tardias e complexas. ${ }^{41}$ Há também a ambiguidade do termo "plebe", já que tal status não era exclusivo aos mais pobres mas também incluía famílias relativamente abastadas. Entretanto, no contexto em questão, Lívio parece estar descrevendo uma decisão da maioria ("todas as 35 tribos votaram 'sim”"); e mais: uma decisão majoritária tomada contra a vontade de um dos cônsules, que queria que a guerra continuasse para que ele pudesse obter um triunfo sobre os macedônios. Assim, o testemunho de Lívio sugere a possibilidade de que certas decisóes populares podiam ir contra os interesses de sumos magistrados, e mesmo assim entrar em efeito.

Além das declarações de guerra e tratados de paz, as narrativas sobre fundação de colônias parecem contar sempre com algum tipo de ação popular. Embora a decisão de fundar uma colônia fosse executada formalmente pelo senado, por meio de um senatus consultum, ela parece ter sido seguida de um plebiscitum — isto é, uma decisão do conselho da plebe, que montava a comissão de magistrados encarregados de organizar a colônia.

\footnotetext{
${ }^{38}$ HÖLKESKAMP, Karl-Joachim. Reconstructing the Roman Republic: an Ancient Political Culture and Modern Research. Princeton: Princeton Univesity Press, 2010, p. 19-20.

39 FLAIG, Egon. Ritualisierte Politik. Zeichen, Gesten und Herrschaft im Alten Rom. Gottingen: Vandenhoeck \& Ruprecht, 2003, p. 155-174, 184-193.

${ }^{40}$ LÍVIO 33.25.4-7: (And the consul might have won his point, had not Quintus Marcius Ralla and Gaius Atinius Labeo, tribunes of the people, announced that they would veto any action if the question was not first referred to the assembly whether they wished and ordered that peace be made with King Philip. This motion was then laid before the people convened on the Capitoline; all the thirty-five tribes voted "aye" [tradução do autor]); (Et forsitan obtinuisset consul, ni Q. Marcius Ralla et C. Atinius Labeo tribuni plebis se intercessuros dixissent, ni prius ipsi ad plebem tulissent vellent iuberentne cum rege Philippo pacem esse. Ea rogatio in Capitolio ad plebem lata est; omnes quinque et triginta tribus "uti rogas" iusserunt).

${ }^{41}$ OAKLEY, Stephen. A Commentary on Livy, Books VI-X. Oxford: Oxford University Press, 1997-2005, p. 72-99.
} 
Por um lado, a colonização teria sido interessante para as camadas populares, sobretudo para aqueles cidadãos mais pobres, para quem a perspectiva de adquirir terras teria representado a forma mais eficaz de ascensão social e melhoria nas condiçóes de vida. ${ }^{42}$ Seria de se esperar, portanto, que os setores populares fossem favoráveis à criação de colônias em terras conquistadas, e que eles ativamente apoiassem tais medidas nas assembleias. Por outro lado, é também verdade que as elites romanas estavam interessadas em saciar a "fome de terras" do povo, de modo a diminuir o descontentamento popular e evitar instabilidades. Ademais, em alguns casos a vantagem de possuir um lote de terra pode ter sido anulada por desvantagens como a grande distância da colônia em relação a Roma, ou sua localização em áreas vulneráveis a ataques inimigos. ${ }^{43}$

Ao voltarmos às fontes, novamente encontramos uma linguagem formulaica, nas várias instâncias em que Lívio afirma: "o senado e o povo autorizaram a criaçáo de uma colônia." ${ }^{\text {"4 }}$ O caráter padronizado desse tipo de notícia gera suspeitas acerca da real importância da decisão popular. De qualquer forma, é significativo que a permissão do senado para tais empreitadas não é sequer mencionada em alguns casos. Um exemplo é o trecho em que Lívio discute a criação de cinco colônias no litoral tirreno da Itália em 194 a.C. (Volturnus, Liternus, Puteoli, Castrum Salerni e Buxentum). Lívio apenas nota que: "foi decidido que cada colônia deveria incluir 300 casas, e três comissários foram nomeados para supervisionar o caso. ${ }^{345}$

Ainda mais interessante é o trecho em que Lívio narra a concessão de cidadania romana a certas comunidades estrangeiras. $\mathrm{O}$ episódio em questâo teria ocorrido em 188 a.C., quando surgiu um debate acerca da concessão de cidadania aos habitantes de Fundi, Formiae, e Arpinum, três cidades no sul da Itália que até aquele momento possuíam a "cidadania sem o voto" (civitas sine suffragio):

Um dos tribunos da plebe, C. Valerius Tappo, apresentou uma proposta de conceder a cidadania romana completa aos cidadãos de Formiae, Fundi e Arpinum. Eles tinham até então possuído a cidadania sem o poder de voto. A proposta foi contestada por quatro tribunos, os quais

\footnotetext{
${ }^{42}$ Cf. SCOPACASA, Rafael. Rome’s Encroachment on Italy. In: COOLEY, Alison E. (Org.). A Companion to Roman Italy. Oxford: Wiley Blackwell, 2016, p. 35-56.

${ }^{43}$ Cf., por exemplo, LÍVIO 10.21.7-10, sobre a dificuldade de encontrar cidadãos romanos dispostos a ocupar as colônias recém-fundadas de Minturnae e Suessae, no sul da Itália, em 295 a.C., por causa da proximidade de territórios inimigos.

${ }^{44}$ LIVIO 35.40.5-6: (During the year the senate and people authorised the formation of a military colony at Vibo; 3700 infantry and 300 cavalry were sent there [tradução do autor]); (Eodem hoc anno Vibonem colonia deducta est ex senatus consulto plebique scito. Tria milia et septingenti pedites ierunt, trecenti equites).

${ }^{45}$ LIVIO 32.29.3-4; (C. Atinius, one of the tribunes of the plebs, carried a proposal for founding five colonies on the coast, two at the mouths of the Volturnus and Liternus, one at Puteoli, one at the Castrum Salerni, and finally Buxentum [tradução do autor]); (C. Atinius tribunus plebis tulit ut quinque coloniae in oram maritimam deducerentur, duae ad ostia fluminum Vulturni Liternique, una Puteolos, una ad Castrum Salerni: his Buxentum adiectum).
} 
alegaram que a proposta não tinha recebido a sanção do Senado; mas, ao serem informados que cabia ao povo (populus), e não ao Senado, conferir a cidadania a quem eles escolhessem, os tribunos abandonaram sua oposição. ${ }^{46}$

O que mais chama a atenção nesse trecho é o fato de que parecia haver certa confusão a respeito do procedimento a ser seguido. Mais especificamente, parecia não haver muita clareza sobre quem deveria decidir se a concessão de cidadania romana para as comunidades estrangeiras seria feita ou não. A civitas sine suffragio costumava ser vista na historiografia como um estágio intermediário no processo de assimilação das comunidades estrangeiras a Roma. ${ }^{47} \mathrm{~A}$ ideia era que Roma concedia primeiro a cidadania "sem o voto", para que a comunidade pudesse começar o processo de assimilação às instituições e à cultura romanas. No entanto, o trecho citado é a única referência que conhecemos a cidadãos "sem sufrágio" que recebem o direito de voto — ou seja, que adquirem cidadania plena. ${ }^{48}$ Algo semelhante pode ter ocorrido no caso das comunidades sabinas cujas terras foram provavelmente confiscadas pelos romanos por volta de 290 a.C. Aqueles sabinos que não foram mortos ou expulsos provavelmente receberam algum tipo de cidadania parcial. ${ }^{49}$ Eles, ou seus descendentes, foram provavelmente emancipados em 241 a.C., com a criação das tribos Quirina e Velina. ${ }^{50}$ No entanto, é difícil generalizar a partir desses casos isolados. Como vimos, uma leitura atenta do trecho de Lívio sugere que os próprios romanos não tinham certeza sobre quando e como a concessão de cidadania plena poderia ser feita, o que sugere a inexistência de um procedimento fixo. ${ }^{51}$ Contudo, parece significativo que, ao final do debate, chega-se ao consenso de que cabe ao povo, e não ao senado, decidir.

Por fim, o povo (novamente entendido como "maioria") figura como participante decisivo também em episódios de julgamento de grandes comandantes militares. Um bom exemplo é a narrativa de Políbio sobre as acusações feitas contra Scipião Africano, o general que derrotara Cartago em 202 a.C., e que logo em seguida coordenara a distribuição de terras no

${ }^{46}$ LÍVIO 38.36.7-9: (One of the tribunes of the plebs, C. Valerius Tappo, brought forward a proposal granting the full franchise to the citizens of the municipal boroughs of Formiae, Fundi and Arpinum. They had hitherto enjoyed the citizenship without the power of voting. This motion was opposed by four of the tribunes on the ground that it had not received the sanction of the senate, but on being informed that it rested with the people and not the senate to confer the franchise on whom they chose, they abandoned their opposition [tradução do autor]); (De Formianis Fundanisque municipibus et Arpinatibus C. Valerius Tappo tribunus plebis promulgavit ut iis suffragii latio-nam antea sine suffragio habuerant civitatem - esset. Huic rogationi quattuor tribuni plebis, quia non ex auctoritate senatus ferretur, cum intercederent, edocti populi esse, non senatus, ius suffragium quibus velit impertire, destiterunt incepto).

${ }^{47}$ HUMBERT, Michel. Municipium et civitas sine suffragio: l'organisation de la conquête jusqu' à la guerre sociale. Roma: École Française de Rome, 1978.

${ }^{48}$ Cf. MOURITSEN, Henrik. The Civitas sine Suffragio: Ancient Concepts and Modern ideology. Historia: Zeitschrift für Alte Geschichte. Wiesbaden: F. Steiner Verlag, v. 56, n. 2, p. 144, 2007.

${ }^{49}$ BRUNT, Peter. The Enfranchisement of the Sabines. In: BIBAUW, Johannes (Org.). Hommages a M. Renard II. Bruxelas: Latomus, 1969, p. 121.

${ }^{50}$ LÍVIO Periochae 19; AFZELIUS, Adam. Die römische Eroberung Italiens (340-264 v. Chr.). Acta Jutlandica. Aarhus: Aarhus University Press, v. 14, 1942.

${ }^{51}$ MOURITSEN, Henrik. The Civitas sine Suffragio: Ancient Concepts and Modern Ideology, op. cit., p. 144-5. 
sul da Itália para soldados que haviam participado da sua expedição vitoriosa contra Aníbal. Políbio deixa claro que o julgamento foi feito perante "os muitos" — hói pollói. No meio dos procedimentos, Scipião teria feito um apelo ao povo reunido, declarando: "Não é adequado que o povo (demos) romano tenha que ouvir acusaçóes contra Scipiáo, o homem a quem os seus acusadores devem a sua própria liberdade de expressão." Segundo Políbio, em resposta ao apelo de Scipião o povo dispersou-se "deixando o acusador sozinho". ${ }^{52}$ Aparentemente, cidadãos que quisessem processar personalidades populares precisavam manter a multidáo ao seu lado: a perda da opiniáo popular favorável significava a perda de legitimidade de todo o processo. Disso podemos inferir que parte do poder popular se devia aos números, à "multidáo" que se reunia e se fazia ouvida, e cuja aprovação (ou não) tinha um impacto considerável na legitimidade dos procedimentos jurídicos.

\section{Conclusão}

Todos esses episódios de aparente intervenção popular, em momentos decisivos da expansão romana, náo passariam de "farsas"? Ou seriam eles uma indicação de que a hegemonia romana foi o fruto da vontade política das massas, ao menos em parte?

Conforme vimos no início deste artigo, um dos argumentos mais sólidos em favor da tese oligárquica é o de que as assembleias davam mais peso aos votos dos ricos do que dos pobres. Supóe-se frequentemente na historiografia que o sistema eleitoral romano garantia a maioria dos ricos em todas as votaçôes, já que o número de centúrias e tribos "mais ricas" teria sido maior do que as centúrias e tribos "pobres". Entretanto, o desenvolvimento da historiografia nos últimos anos deixou claro que ainda sabemos extremamente pouco sobre como esse sistema eleitoral funcionava, ou sobre como ele (provavelmente) mudou ao longo dos cinco séculos de história republicana. Embora as assembleias (das centúrias e das tribos) pudessem dar um peso maior para o voto dos cidadãos mais ricos, não é claro até que ponto elas marginalizavam o voto dos cidadáos mais pobres. ${ }^{53}$ Ademais, levando em conta as frequentes rivalidades entre diferentes famílias aristocráticas, não parece realista pressupor que a "aristocracia romana" como um todo sempre agia de modo coeso na esfera política, como se seus "interesses de classe" sempre falassem mais alto do que as rixas que dividiam as famílias individuais. Talvez esse seja mais um caso em que os pressupostos dos historiadores modernos, como por exemplo

${ }^{52}$ POLÍBIO 23.14.1-4: ('It ill-became the Roman people to listen to accusations against P. Cornelius Scipio, to whom his accusers owed it that they had the power of speech at all.' At this the populace dispersed, and quitting the



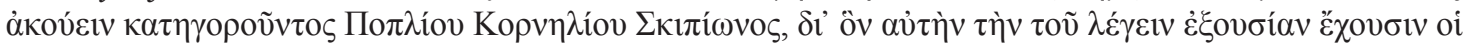

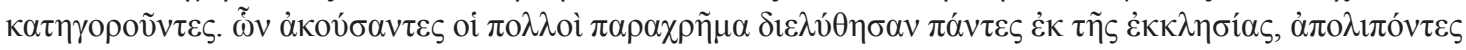

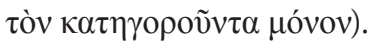

${ }^{53}$ Sobre o funcionamento das assembleias, as lacunas no nosso conhecimento e o perigo de pressupostos não questionados, cf. YAKOBSON, Alexander. Popular power in the Roman Republic, op. cit., p. 393. 
o conceito de "classe social", tenha prejudicado nosso entendimento da realidade romana. Especialmente se considerarmos que a história da república é repleta de instâncias em que a aristocracia romana não se comporta como uma classe social politicamente unida. ${ }^{54}$

Talvez o indício mais claro de que as decisôes populares não eram meras encenaçóes é o fato de que, pelo que indicam nossas fontes, os membros da elite se preocupavam genuinamente e constantemente em obter apoio popular e em controlar a opiniáo pública. Precisamos, antes de tudo, reconhecer que a relação entre povo e elite na Roma republicana era complexa. Os aristocratas, ou nobiles, viviam em uma cultura de competição intensa. ${ }^{55}$ Ter uma carreira política era essencial para a manutenção do status e do prestígio das grandes famílias, de modo que seus integrantes precisavam competir ferozmente entre si para conseguir ser eleitos às magistraturas. Isso sugere que as massas não eram completamente passivas, ou totalmente manipuladas pelas obrigaçóes do clientelismo; pelo contrário, elas tinham um poderoso trunfo nas suas mãos: isso explicaria por que, para a elite, a opiniáo popular importava tanto.

Os nobres buscavam ultrapassar seus rivais conquistando apoio popular nas eleições. Como parte dessa dinâmica, esperava-se que candidatos caminhassem pelo fórum "apertando as mãos e abraçando várias pessoas, a quem ele [o candidato] pedia para que votassem nele". ${ }^{56}$ Contudo, em longo prazo essa dinâmica acabou por gerar um sério paradoxo no seio da aristocracia: tornou-se cada vez mais comum que aristocratas particularmente ambiciosos decidissem apoiar causas populares mais radicais. $\mathrm{O}$ caso mais conhecido, embora controverso, é o da proposta de reforma agrária apresentada por Tibério Graco em 133 a.C. Quaisquer que possam ter sido as motivaçôes pessoais que levaram Tibério Graco (e, posteriormente, seu irmão Caio) a propor a reforma — o simples desejo de agradar a multidão e assim conquistar votos, ou uma sincera crença de que a reforma melhoraria a situação dos pobres, ou uma mistura dessas duas motivaçóes - temos aqui uma instância em que o povo de certa forma "ditava" as regras do jogo; os aristocratas que tinham também que seguir as massas, e não somente o contrário. Por isso, a antiga dicotomia entre "oligarquia" e "democracia" deve, talvez, ser abandonada em prol de estudos que enfoquem justamente as formas de comunicação e de negociação entre as massas e as elites na república romana.

Se for plausível concluir que as camadas populares estavam influenciando o rumo da expansão hegemônica romana, uma série de outras questóes vem à tona: quais seriam os interesses, be-

${ }^{4}$ ROSENSTEIN, Nathan. Competition and Crisis in Mid-Republican Rome. Phoenix, Toronto, v. 47, p. 313-338, 1993.

${ }^{55}$ Idem; ROSENSTEIN, Nathan. Aristocratic Values. In: ROSENSTEIN, Nathan; MORSTEIN-MARX, Robert (Orgs.). A Companion to the Roman Republic. Oxford: Blackwell, 2006, p. 365-382.

${ }^{56}$ POLÍBIO 26.1.5; (shaking hands and embracing various people whom he entreated to vote for him [tradução

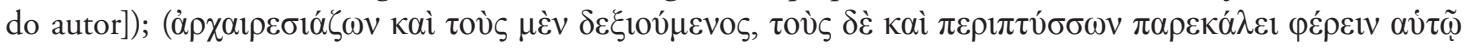
$\tau \grave{\eta} v \psi \tilde{\eta} \varphi \circ v)$. 
nefícios ou vantagens que teriam movido o povo a sustentar uma política expansionista? Se eram, sobretudo, as camadas populares que eram enviadas às colônias, quais seriam as implicaçóes desse fato para o nosso entendimento das trocas culturais, que até pouco tempo eram tratadas pelo viés da "romanização"?57 Em vez de "cultura romana", seria mais exato falarmos em cultura romana popular/"não elite"? Como poderíamos identificar a existência de uma cultura política popular/das massas, quais seriam os seus valores e princípios, e como é que ela dialogava com a aristocracia? Essas e outras questóes permanecem a ser exploradas de maneira mais aprofundada.

\section{Fontes documentais}

Cicero Volume XVI: On the Republic; On the Laws. The Loeb Classical Library. Cambridge Mass.: Harvard University Press, 1928.

Cicero Volume X: In Catilinam 1-4, Pro Murena, Pro Sulla, Pro Flacco. The Loeb Classical Library. Cambridge Mass.: Harvard University Press, 1976.

$C I L=$ Corpus Inscriptionum Latinarum.

Livy Ab Urbe Condita Volume IX: Books 31-34. The Loeb Classical Library. Londres: Heinemann, 1935.

Livy Ab Urbe Condita Volume X: Books 35-37. The Loeb Classical Library. Londres: Heinemann, 1935.

Livy Ab Urbe Condita Volume XI: Books 38-39. The Loeb Classical Library. Londres: Heinemann, 1936.

Polybius: The Histories volume III: books 5-8. The Loeb Classical Library. Cambridge Mass.: Harvard University Press, 2010.

Polybius: The Histories volume V: books 16-27. The Loeb Classical Library. Cambridge Mass.: Harvard University Press, 2012.

Polybius: The Histories volume VI: books 28-39, Fragments. The Loeb Classical Library. Cambridge Mass.: Harvard University Press, 2012.

Sallust: The War with Catiline, The War with Jugurtha. The Loeb Classical Library. Cambridge Mass.: Harvard University Press, 2013.

Suetonius. Lives of the Twelve Caesars Volume I. The Loeb Classical Library. Cambridge Mass.: Harvard University Press, 1914.

\footnotetext{
${ }^{57}$ Para uma apreciação do debate sobre a romanização e abordagens alternativas à questáo do impacto cultural da hegemonia romana, cf. SCOPACASA, Rafael. Repensando a romanização: a expansão romana na Itália a partir das fontes historiográficas. Revista de História (USP), São Paulo, v. 172, p. 113-161, jan./jul. 2015.
} 


\section{Referências bibliográficas}

AFZELIUS, Adam. Die römische Eroberung Italiens (340-264 v. Chr.). Acta Jutlandica. Aarhus: Aarhus University Press, v. 14, 1942.

BRUNT, Peter. The enfranchisement of the Sabines. In: BIBAUW, Johannes (Org.). Hommages a M. Renard II. Bruxelas: Latomus, 1969, p. 121-9.

. Social Conflicts in the Roman Republic. Londres: Chatto and Windus, 1971.

. The Fall of the Roman Republic and Related Essays. Oxford: Clarendon, 1988.

CORNELL, Timothy. The Beginnings of Rome. Londres: Routledge, 1995.

ECKSTEIN, Arthur. Mediterranean Anarchy, Interstate War, and the Rise of Rome. Berkeley: University of California Press, 2006.

- Rome Enters the Greek East: from Anarchy to Hierarchy in the Hellenistic Mediterranean, 230-170 BC. Oxford: Blackwell, 2012.

FLAIG, Egon. Ritualisierte Politik. Zeichen, Gesten und Herrschaft im Alten Rom. Gottingen: Vandenhoeck \& Ruprecht, 2003.

FLOWER, Harriet. Roman Republics. Princeton: Princeton University Press, 2009.

GELZER, Matthias. The Roman Nobility. Oxford: Blackwell, 1969.

HÖLKESKAMP, Karl-Joachim. Reconstructing the Roman Republic: an Ancient Political Culture and Modern Research. Princeton: Princeton Univesity Press, 2010.

HOPKINS, Keith. Conquerors and Slaves. Cambridge: Cambridge University Press, 1978. HUMBERT, Michel. Municipium et civitas sine suffragio: l'organisation de la conquête jusqu' à la guerre sociale. Roma: École Française de Rome, 1978.

MILLAR, Fergus. The Political Character of the Classical Roman Republic, 200-150 BC. Journal of Roman Studies. Londres: Society for the Promotion of Roman Studies, v. 74, p. 1-19, 1984.

MORSTEIN-MARX, Robert. Mass Oratory and Political Power in the Late Roman Republic. Cambridge: Cambridge University Press, 2004.

MOURITSEN, Henrik. The Civitas sine Suffragio: Ancient Concepts and Modern Ideology. Historia: Zeitschrift für Alte Geschichte. Wiesbaden: F. Steiner Verlag, v. 56, n. 2, p. 141-58, 2007.

. Plebs and Politics in the Late Roman Republic. Cambridge: Cambridge University Press, 2001.

NORTH, John. Politics and Aristocracy in the Roman Republic. Classical Philology. Cambridge: Cambridge University Press, v. 85, n. 4, p. 277-287, out. 1990.

OAKLEY, Stephen. A Commentary on Livy, Books VI-X (4 vols.). Oxford: Oxford University Press, 1997-2005. 
RAAFLAUB, Kurt (Org.) Social Struggles in Archaic Rome: New Perspectives on the Struggle of the Orders. Oxford: Oxford University Press, 2005.

ROSENSTEIN, Nathan. Competition and Crisis in Mid-Republican Rome. Phoenix, Toronto, v. 47, p. 313-338, 1993.

. Aristocratic values. In: ROSENSTEIN, Nathan; MORSTEIN-MARX, Robert (Orgs.). A Companion to the Roman Republic. Oxford: Blackwell, 2006, p. 365-382.

SCOPACASA, Rafael. Essere Sannita. Rappesentazioni di uno popolo Italico nelle fonti letterarie e storiografiche antiche. Campobasso: Istituto Regionale per gli Studi Storici del Molise, 2007.

- Repensando a romanização: a expansáo romana na Itália a partir das fontes historiográficas. Revista de História (USP), São Paulo, v. 172, p. 113-161, jan./jul. 2015.

. Rome's Encroachment on Italy. In: COOLEY, Alison E. (Org.). A Companion to Roman Italy. Oxford: Wiley Blackwell, 2016.

SYME, Ronald. The Roman Revolution. Oxford: Clarendon, 1939.

TAYLOR, Lily Ross. Party Politics in the Age of Caesar. Berkeley: University of California Press, 1949.

WISEMAN, Timothy. Remembering the Roman People. Oxford: Oxford University Press, 2009. YAKOBSON, Alexander. Popular Power in the Roman Republic. In: ROSENSTEIN, Nathan; MORSTEIN-MARX, Robert (Orgs.) A Companion to the Roman Republic. Oxford: Blackwell, 2006. p. 383-400.

\section{Como citar}

SCOPACASA, Rafael. Poder popular e expansão da república romana, 200-150 a.C. Topoi. Revista de História, Rio de Janeiro, v. 19, n. 37, p. 80-101, jan./abr. 2018. Disponível em: $<$ www.revistatopoi.org $>$. 